\title{
0 recuo do meridiano de Tordesilhas em face do Direito Internacional
}

\author{
José Dalmo Fairbanks Belfort de Mattos \\ Livre docente de Direito Internacional Pablico
}

Aos 13 de janeiro de 1750 , os plenipotenciários de Portugal e Castela firmavam, em Madrid, um convênió, visando pôr fim às hostilidades entre as duas Corôas. 'O último resquício da Guerra de Sucessão da Espanha, que se arrastava na Península, mau grado o Tratado de Utrecht.

o Visconde de Vila Nova de Cerveira representava Portugal. Os direitos da outra Parte Contratante ficavam sob a guarda de D. José de Carvajal y Lencastre, - minístro inepto da Côrte decadente del Rei Fernando VI ${ }^{\circ}$.

Portugal escolhera bem o momento para negociar.

Sentia-se, no curso das conversações, a influência apaziguadora da Rainha de Espanha, -- portuguesa de nascimento, e devotada à sua terra natal. Sentia-se, também, presente, embora inconfesado, o influxo de ALEXANDRE DE GUSMÃO, - o diplomata santista, símples adido a embaixada lusa. Mas que visava, com seus habels conselhos, consolidar o domínio de seu País sobre as conquistas bandeirantes.

E finalmente, pesava sobre a reunião dos plenipotenciários, - mais positiva do que o éco das batalhas de AImanza, de Vila-Viciosa e do Caia; mais eficiente que as tropas de Schamberg e de Lippe, - o lento trabalho, quasi anônimo, dos desbravadores, de bandeirantes e "frontei- 
ros", que haviam expulso os leões de Castela até as lindes do Perú.

Urgia, por outro lado, consagrar, em texto expresso, a incorporação do território das Minas do Cuiabá e dos Goiazes. Afim de que o velho Rei Dom João $V^{\circ}$, que se finava em Lisbôa, pudesse coroar seu reinado com um tratado triunfal. E, após um longo administrar, vivido em função das riquezas ultramarinas, sentisse o gôzo de vêr, como parte integrante de seu domínio, de facto $e$ de jure, os mananciais de ouro do Mato Grosso e do Guaporé.

Consagrava-se, dest-arte, a política joanina. Mas, por outro lado, obtinha-se a vitória definitiva do expansionismo, no Continente Americano. Que fôra o sonho de D. Manoel, de Afonso $\mathrm{VI}^{\circ}$ e de Pedro $\mathrm{II}^{\circ}$ de Portugal. O "espirito" pluri secular do Conselho Ultramarino.

Essa data, pois, cujo bicentenário se comemorou há poucos anos, reveste-se para nós de excepcional importância diplomática: -

a) Por trazer o primeiro esboço de nossas fronteiras, com o mundo hispano-americano;

b) Por convalidar, em face do Direito Internacional Positivo, a situação de facto, nascida com o espraiar do bandeirismo.

Urge, pois, estudar o Tratado de Madrí, em seu duplo aspéto histórico e jurídico.

É o que vamos fazer, em rápida sintese, nas linhas a seguir.

AS ESPANSÕES COLONIAIS DOS POVOS IBERICOS

Portugal, premido entre Castela e o mar, oscilara por algum tempo, entre duas possibilidades: - a união ibérica, sob hegemonia portuguêsa, ou a construção de um império de ultra-mar.

O progressivo diferenciamento entre osdois povos; o sen timento nacional crescente, que mais e mais se superpunha 
aos eventuais direitos dinásticos, baseados na concepção feudal, fizeram-no compreender, de maneira indiscutivel, ser impossivel a união das Corôas.

E, em pleno século XIV, ainda na Idade Média, Portugal se fazia ao mar. Sob os últimos reis afonsinos. Antes da tomadia de Ceuta. Antes que o Infante Dom Henrique construisse, na Escola de Sagres, as bases da ciência náutica dos grandes navegadores.

Já em 1345, D. Afonso IV ${ }^{\circ}$ o heroi de Salado - comunicava ao Papa Clemente $\mathrm{VI}^{\circ}$ os aprestos que fazia para a conquista das Ilhas Afortunadas (Canárias), para dali extirpar "as varas estéreis da infedelidade".

E lhe dizia, em carta datada de Montemór-o-Novo, aos 12 de Fevereiro, haver,

" mandado as nossas gentes, e algumas naus para explorarem "a qualidade da terra". (1)

A batalha de Aljubarrota, e o fracasso de Afonso $\mathrm{V}^{\circ}$, nos campos de Toro, mostraram, de vez, aos monarcas da Ibéria, ser impossivel unir os dois povos, em uma monarquia unificada.

Burlados em seu expansionismo terrestre, portugueses, catalães e aragoneses fazem-se ao mar. Barcelona domina o Mediterrânio Ocidental. O Consolato del Mare consagra, em texto, os usos e costumes de seus mercadores. E torna-se a grande lei reguladora do comércio, desde Cadiz, até as ribas meridionais da Itália.

Aragão conquista as Baleares. Anexa Nápoles, a Sardenha e a Sicilia.

Portugal busca, no Atlântico, construir o seu Império.

(1) Tradução de Joaquim José da Costa de Macedo e José Pedro da Costa, in "História da Colonização Portuguesa no Brasil”, vol. I.o (introdução) pág. LXVII. 
E, em 1418, Bariolomeu Perestrêlo chega a Porto Santo. Em 1419, Gonsalves Zarco e Tristão Vaz Teixeira arribam à Madeira. Seis anos após, estas ilhas se povoam. E em 1431, uma grande expedição singra, ao mando do Infante D. Henrique, a varejar o Mar da Treva.

D. João II $^{\circ}$ intitula-se Rei da Guiné. Cruza-se o Cabo de Não; atinge-se S. Tiago de Cabo Verde, lá por 1456, no limiar da Idade Moderna, após 1.510 milhas de navegação.

\section{A "CRISTANDADE" E O PROBLEMA DA SOBERANIA TER- RITORIAL}

Ora, a êsse tempo, a simples ocupação não bastava para integrar a "res nullius" à soberania de um Estado cristão.

A Cristandade constituia, de fato, uma familia de Nações, solidamente assente no background de uma mesma cultura, e da religião comum.

O Papa era o Chefe desta "Respublica sub Deo". Intervinha em assuntos internacionais, óra ratione feudi, ora ratione peccati.

Confirmava as autoridades que the solicitavam a in. vestidura. $\mathrm{Ou}$ as destituia, quando incursas em sanções eclesiásticas, ou criminais.

Chegava mesmo, com o consenso unânime dos Principes, a estatuir qual o titular da soberania, em casos duvidosos: empossando os Carlovíngios, no trono de França, atribuindo a Inglaterra a Guilherme, o Conquistador; depondo D. Sancho $\mathrm{I}^{\circ}$ de Portugal...

$\mathrm{E}$, sobre as ihas de ultramar, cria-se caber-lhe a sobera. nia virtual, não só como Autoridade Suprema da "Respublica Christiana", como tambem derivante da controver. tida "Doação de Constantino".

Cabia-lhe, pois, distribuir entre os soberanos cristãos, as terras descobertas, ou conquistadas ao infiel. 
Exemplos abundavam. Urbano IV $^{\circ}$ concedera, no séculoXI, a Córsega ao Bispo de Pisa. Em 1155, Henrique $\mathrm{Il}^{\circ}$ de Inglaterra solicitava a Adriano IV $^{\circ}$ que the reconhecesse soberania sobre a Irlanda. Prometia-lhe:

"to provide instruction for an ignorant people. to extirpate vice from the Lord's vineyard".

E que

"as every Christian island was the property of the Holy Sea he dit not presume to make the attempt without the advice and consent of the successor of Saint Peter" (John Lingard - HISTORY OF ENGLAND, pág. 133) .

E suas pretensões foram acolhidas, pela Bula "Laudabiliter", do mesmo ano.

$\mathrm{E}$ isto, reconheciam-no todos. Proclama-o, em 1316, Pierre Dubors, em seu "De recuperatione Terrae Sanctae". Em 1420, Jerzy de Podjebrad, - rei hussita da Boêmia (mau grado afastado de Roma pelo scisma). inclui-o entre os "poteres a latere", que atribuia ao Romano Pontífice', para concretizar-se o plano de paz perpétua.

$\mathrm{E}$ os Reis de Portugal dirigem-se ao Papa, em sua dupla investidura de soberanos e de Mestres da Ordem de Cristo. E obtêm bulas de confirmação.

A 8 de Setembro de 1433, o Papa EugÊNio IV ${ }^{o}$ proclama ao Mundo, que ficam sujeitas a El Rei D. Duarte e seus sucessores, as terras que os mesmos conquistaram aos Infieis. (Bula Rex Regum)

Sete anos mais tarde, a 9 de Janeiro de 1442, declara textualmente confirmar as doações feitas pelos reis portugueses à Ordem de Cristo. E concede-lhes, entre outros poderes, jurisdição sobre 
"as ilhas sitas no Mar Oceano." (Bula "Etsi Suscepti") Sucedem-se os Pontifices, e as Bulas se sucedem.

Nicolau $V^{o}$ confirma aos Reis de Portugal. "todas as conquistas feitas em África, com as ilhas sitas nos mares adjacentes, desde o Cabo de Não, até o Sul da Costa da Guiné".

XISTO IV , pela bula “Aeterni Regis", passada em Roma aos 21 Junho 1431, estende a jurisdição lusa até a India Confere a parte espiritual do "descoberto" à Ordem de Cristo. Mantem a autorização dantes concedida aos portugueses, para que possam

"fazer com quaesquer Mouros e Infieis, de quaesquer cousas e bens, e vitualhas, e compras e vendas".

E mais :-

"fazer com ditos Mouros e Infieis",

quaisquer transações e mercancias, desde que lhes não vendessem ou dessem,

"ferramenta, liame, cordoalha, navios, ou qualquer gênero de armas".

Enquanto o império português assim se alicerçava, em sólidos fundamentos juridico-canônicos, a diplomacia leiga negociava acordos. E creava, assim, um segundo esteio à soberania temporal dos Reis, sobre as terras que se desvendavam.

Assim, já aos 6 de Março de 1480, Fernando e Isabel firmavam com Afonso $V^{o}$ de Portugal um celebre Convênio, pelo qual recebiam as Canárias. Mas reconheciam à Corôa Portuguesa a 
"posesion, casi posesion en que estan em todos los tratos, tierras, rrescates de Gujnea, con sus minas de oro, e qualesquier otras yslas, costas, tierras descubiertas e por descubrir, falladas y por fallar, yslas de la Madera, Puerto Santo, e Desierta, y yslas de las Flores.

Não ficava aí o ról. Ia além e continuava:-

“. .e asy las yslas de cabo Verde, e todas las islas que agora tiene descubiertas, e qualesquier otras islas que se fallaren o conquieriren, de las yslas de Canarias contra la Gujnea, porque todo lo que es fallado e se fallare; conquerir o descobierto, finca a los dichos Rey e Principe de Portugal, e sus reynos, tirando solamente las islas de Canaria. ."

Esse longo acerto é confirmado, no ano seguinte, pelo Papa Xisto IV ${ }^{\circ}$

Portugal parece triunfar inteiramente. Mas, nessa cláusula final de aceitação, os Reis de Aragão e Castela haviam deixado, implícita, a chave de reivindicações futuras às teras do Ocidente.

Reconhecia-se a Portugal o senhorio de terras e águas, sobre ilhas e portos, minas e populações. Mas apenas "de las yslas de Canaria contra la Gujnea”. E não sobre - Mar Ocidental.

As águas do Poente, - o temeroso "Mar da Noite" continuavam como "res nullius". E "res nullius" ficavam a lendária Antília, a "Ilha da Brandam", e a "Ilha dos Sete Bispos", - que os relatos medievais punham nos confins do mundo. E diziam ter sido evangelizada por sete prelados de Espanha, que fugiam, no século VII ${ }^{\circ}$, ao jugo do Islam. .. 
AS PRIMEIRAS BULAS DE ALEXANDRE VI.o

Doze anos mais tarde, Colombo atingia as Ilhas $\mathrm{Ba}-$ hamas.

A 15 de Março de 1493, voltava a Palos, de onde singrara. Em Abril, era recebido por Fernando e Isabel. A 3 de maio, o Papa Alexandre $\mathrm{VI}^{\circ}$ expedia duas bulas, visando a catequese no Novo Mundo.

A primeira, - a "Eximiae Devotionis" — concede aos. Reis de Leão e Castela e seus descendentes,

“as terras firmes, ilhas, remotas e incógnitas, descobertas e por descobrir, para as partes ocidentaes e mar Oceano, com seus privilegios, imunidades, graças e liberdades, de que desfrutavam os Reis de Portugal, nas partes da A'frica, Guiné: e Costa d'Oiro".

$\mathrm{E}$, pela "Inter Coetera" recebiam os Reis de Espanha: "et singulas terras et insulas predictaes, sic incognitas et hactenus per nuntios vestros repertas e reperiendas in posterum, quae sub dominio actuali temporali aliquorum principum christiano". rum non sint."

Essa doação, feita prela "plenitude do Poder Apostolico" era, porém, gravada de um onus. Cabia aos Rels. Católicos enviar às terras aludidas, missionários bastantes para dilatar o orbe Cristão. Como, aliás, o declaravam as bulas anteriores, que atribuiam terras a soberanos cristãos.

A primeira Bula "Inter Coetera" não traçava limites. geográficos à expansão castelhana. Apenas excluia as terras, já àquela época sob o domínio dos príncipes da Cristandade. 
Poderiam, pois os espanhois investir para Leste e rumo ao Poente, e assenhorear-se de quaisquer terras de gentios ou infieis, onde já não os houvesse precedido o padrão das quinas portuguesas.

Não era essa, entretanto, a verdadeira intenção do Pontífice. Ou então os inconvenientes de tal amplitude foram-lhe logo ponderados.

Pois, no dia subsequente, uma segunda Bula, - igualmente denominada "Inte $e_{r}$ Coetera" fazia correr de Polo. a Polo, uma linha ideal, traçada

"a qualibet insularum quae vulgariter nuncupantur de los Azores et Caboverde centum leucis versus occidentem et meridiem.."

$\mathrm{E}$ somente ao $\mathrm{S}$. e a W. desta linha poderiam os espanhois adquirir soberania territorial. E, ainda assim, sobre terras que

"peralium regem aut principem christianum non fuerint actualiter possesse",

até o dia de natal precedente, no qual começara a fluir o ano litúrgio de 1493.

Esta concessão papalina ecoou dolorosamente em Lisbôa.

Não poderia, porém, D. João $\mathrm{II}^{\circ}$ impugnar a legitimidade em si do ato pontifício.

Fazê-lo, seria pôr em dúvida o poder de interferência papal em negócios seculares, em assuntos pertinentes ao bem da Cristandade. $\mathrm{E}$ tal direito constituia o fundamento do Direito Internacional da época. Único elemento que tornava possivel a existência da "Respublica" sub Deo", como todo orgânico, deante da ameaça da. mourisma. 
Demais, negá-lo, seria negar a carta de Afonso IV a Calixto $\mathrm{II}^{\circ}$. Seria pôr em jogo o fundamento legal da própria expansão lusa, - todos os privilégios que assegurava aos portugueses a conquista e o comércio do Oriente.

O "Príncipe Perfeito" protestou, apenas quanto ao caso concreto.

Ponderou à Cúria Romana que, se Colombo atingira, como pretendia, o Catai e Cípango, taes áreas já estariam incluidas no domínio português. Pois a jurisdição lusa sobre ditas terras do chá e da seda estaria prevista pela doação de Eugênio IV $^{\circ}$.

Aceitava, pois, o fundamento jurídico da Bula. Negava-lhe aplicação, por incidir sobre áreas já nominalmente apropriadas, embora não estivessem na posse real e efetiva da Corôa lusa.

A nota do Rei português foi regeitada. Nem podia deixar de sê-lo. Pois o dominio português se estenderia, pelos documentos anteriores até a Índia. $\mathrm{E}$ não atingia as terras do Extremo Oriente, - o lendário Pequim de Marco Polo.

Aliás, se tais áreas estivessem na órbita lusitana, o remédio encontrar-se-ia na própria Bula: seriam portuguesas se estivessem "sob domínio temporal atual" do Rei D. João II $^{\circ}$.

Este não se dá por batido. Ordena a Rui de Sande que proteste junto ao Rei de Castela. Nega-se a receber as credenciais de Lope de Herrera, - o enviado extraordinário espanhol. Envia a Madrí Pedro Dias e Rui de Pina, a propôr a partilha do Mundo por outro meridiano.

"linea tomada desde las Canarias contra el Poniente..." 
Responde a Corôa de Castela obtendo do Pontífice a Bula "Dudum Siquidem", revogando expressamente quaisquer por este feitas, ou por seus precessores. $E$ incluindo, na esfera de Espanha,
"todas e cada uma das ditas ilhas, e terras fir- mes, achadas e por achar, descobertas e por des- cobrir, as quaes navegando ou caminhando para o mesmo Ocidente ou Meio Dia, estejam ou te- nham estado e aparecido, ou existam, nas partes meredionais, Orientais e da India.

Em consequência, um frêmito de guerra abala a Peninsula. D. João apresta uma grande frota para rumar ao Ocidente. O Duque de Medinasidonia pede autorização aos Reis da Espanha para velejar em seu rasto, e dar-lhe eventual combate, nos mares do Descoberto.

Mas Castela está esgotada economicamente. A guerra de Granada exauriu-lhe o tesouro. As próprias joias da Rainha encontram-se dadas em penhôr, para equipar a frota de Colombo.

Prosseguem as negociações. $\mathrm{E}$, aos 7 de Junho de 1494, no longinquo burgo de Tordesilhas, firmava-se o célebre Acôrdo, a partilhar o Mundo, que surge para a vida internacional.

Intitulava-se officialmente "Capitulación de la Partición del mar Oceano". Porque, naquele século XV, que findava em meio das navegações e das conquistas, - o mar era o principal. E o mais: - - ilhas e terras, e praias e jazidas era o accessório, o contingente, o aleatório, o presente trazido pelo mar...

O Acôrdo foi ratificado três meses após, em Setubal em - 5 de Setembro de 1494), e confirmado, aos 24 de Ja- 
neiro de 1506, pela Bula "Ea quae pro bono pacis", assinada pelo Pontifice Julio $\mathrm{II}^{\circ}$, a pedido de D. Manuel.

E, por êsse Convênio, Don Gutierrez de Cardenas e Don Enrique Enriquez, por parte de Espanha, e D. Rui de Souza, Senhor de Sagres e Beringel, seu filho João de Souza, almotacel-mór e Aires de Almeida, corregedormór e conselheiro real, traçam.

"pelo dito mar Oceano, uma raia ou linha direita de polo a polo".

Corre ela, não mais a cem léguas do Cabo Verde, e sim a trezentas e setenta léguas dos Açores, - contadas

"em graus ou por outra maneira, que melhor e mais rapidamente se possa efetuar".

Partilha-se, dest'arte, o Mundo Novo. Terras ainda por descobrir, áreas por devassar. Título precedendo a posse. Recaindo, por grosso, sobre o que se viesse a apurar um dia.

CARATER JURİDICO DOS DIREITOS PARTILHADOS.

Alguns autores têm procurado recentemente diminuir a importância internacional das Bulas de Alexandre $\mathrm{VI}^{\circ}$, e do tratado, que as modificou.

Nys foi o primeiro a negar-lhes aspeto dirimidor de controversias. Charles Goyau, no Curso, proferido em Haia, àcerca do "Catholicisme et le Droit des Gens" confessa não haver lido o texto. Mas pergunta se seu alcance não haverá sido exagerado.

MACED SOARES (Fronteiras do Brasil no regimen colonial, pág. 14) nega que a Bula "Inter Coetera" haja dividido o mundo em metades.

Para Capistrano de Abreu, o "arreglo" de Tordesilhas "foi meramente formal e teórico". Oswaldo Aranha vê, na demarcação aludida, uma limitação 
"mais teórica do que real, mais espiritual do que temporal, mais religiosa que geográfica" (ap. Brenno Machado Vieira Cavalcanti - Natureza juridica do mar, pág. 10).

\section{A nosso vêr, no entanto: -}

$\left.1^{\circ}\right)$ as Bulas e Tratados visaram, não apenas delimitar as "zonas de influência", ou catequese, encargos espirituais e os respectivos onus, - mas, também, traçar, realmente Fronteiras, no sentido jurídico do termo;

$2^{\circ}$ ) Os Papas signátarios das Bulas concediam, e os Reis, signatários dos Pactos, mutuamente se reconheciam poderes soberanos sobre as terras, objeto destes atos jurídicos;

$3^{\circ}$ ) Tais poderes soberanos atingiram não apenas as terras, mas ainda as águas adjacentes ou contiguas. E atribuiam aos respectivos titulares o direito de regulamentar o comércio e o acesso a estas áreas.

A prova é sobejamente facil.

As afirmativas supra defluem do texto expresso dos documentos em questão.

Xisto IV', na Bula “Aeterni Regis", reconhece que os soberanos portugueses fizeram explorar a África por seus subditos; que

"com ajuda somente dos ditos naturais, fizerom descobrir as ditas províncias e aquiriron e possuiron como dito he, como verdadeiros senhores, os ditos portos, insulas e mares".

E, porisso, dá-lhes faculdades, implicando a soberania:- 
"O dito Rei Dom Affonso, ou o dito Infante, per sua autoridade acquiria e possuia justa e legitimamente as ditas ilhas, terras, portos e mares, os quais pertenciam de direito ao dito rei Dom Affonso e a seus sucessores".

Comina penas eclesiásticas contra quem os perturbe no gozo das terras assim adquiridas.

Eugênio $\mathrm{IV}^{\circ}$. declara que as terras tomadas aos infieis pertencerão a Affonso $V^{o}$ e seu sucessores.

Alexandre VI ${ }^{\circ}$, por seu lado, declara doar, conceder e assinar aos Reis de Castela e Leão a área concedida pela "Eximiae Devotionis" para sempre, e

"com todos os seus dominios, cidades, castelos, logares, vilas, direitos e jurisdições"

Lógicamente, o mesmo se conclui. Disseram-no, no século XVII, Vittoria e Suarez, embora negassem ao Papa o direito de doar terras pertencentes a gentios.

Reconheceu-o Francisco I. $^{\circ}$ de França, quando diz querer vêr a cláusula do testamento de Adão, que o privava do condomínio sobre terras do Ocidente.

Proclamou-o, enfim, no seicentismo, o Pe. Serafim de Freitas, quando, respondendo ao "Mare Liberum" de Grócio, buscou nas Bulas e Tratados o fundamento legal do "Justo Imperio Lusitanorum Asiatico".

Nem se diga que a "marcação" de Alexandre $\mathrm{VI}^{\circ}$ não criava fronteira, no sentido geográfico do termo,

Se fronteira é a linha de divisão, que separa jurisdições soberanas; se tanto o é a fronteira natural como a tracejada por linhas ou meridianos, ao sabôr das contingências diplomáticas, nâo ha que negar tal carater ao círculo máximo determinado pelo Pontífice.

Era creado por uma autoridade religiosa, e garantido pela excomunhão lata sententia, em que incorreria qual- 
quer transgressor. Mas constituia, tambem, traçado politico, para valer de jure, entre os Estados vizindários.

E, tanto asim era, que o Tratado de Tordesinhas declarava:

"que tudo o que até aqui se tenha achado e desco"berto, e daqui por deante se achar e descobrir pelo "dito senhor rei de Portugal e por seus navios... "desde a dita raia e linha dada na forma supraci"tada, indo pela dita parte do levante, dentro da "dita raia. CONTANTO QUE NÃO SEJA ATRA"VESSANDO A DITA RAIA, que tudo seja e fique " e pertença ao dito senhor Rei de Portugal e a seus "sucessores para sempre.."

Ora, uma linha, que separa possessões; linha que é defeso atravessar; linha, cuja travessia sem prévia licença constitue ilícito canônico e ilícito internacional, - que é senão Fronteira, limite, demarcando RAIA lindeira, no dizer dos próprios negociadores?

Mesmo que se quizesse negar valôr jurídico aos diplomas papalinos (absurdo, frente ao Direito Internacional da época) lá estariam acôrdos diplomáticos, negociados, assinados solenemente por plenipotenciários, munidos de credenciais bastantes, ratificados pelos Reis. E confirmados, mais tarde, por novas bulas. Sancionadas por novas cominações religiosas.

Os atos pontifícios, ao distribuir as terras silenciavam, algumas vezes, quanto ao domínio do mar.

Admitiam, entretanto, os juristas italianos existir um "mar territorial"; na largura de cem milhas. Era a "dioce$s e$ " do litoral, segundo CUJACIO. E tal faixa marítima constituia "mar fechado", cujo acesso ficava ao arbítrio do Estado litorâneo. 
Essa era uma norma quasi universal.

Já no século XII, o "Black book of the Admiralty" mencionava, como parte integrante do território de Inglaterra, "the sea belonging to the King of England".

Gênova intitulava-se dominadora do Mar Ligúrico. Veneza consorciava-se anualmente com o Adriático. E a Inglaterra apelidava a Mancha de "British Channel", e por três vezes iria à guerra com a Holanda, afim de assegurar o respeito a seus direitos senhoriais. $\mathrm{E}$ por três vezes, lhe imporia os navios bátavos saudarem o pavilhão britânico, quando cruzassem navios de Sua Magestade, nos Estreitos de San Patrick, Bristol, São Jorge, em águas da Irlanda, ou no Atlântico Norte. (2. ${ }^{\circ}$ Tratado de Westminster, de 9 de Fevereiro de 1674, art. 13).

E não éra só. Espanha reclamaria direitos absolutos sobre o Mar do Sul. A Rússia imporia sua jurisdição plena sobre o Mar Cáspio, e aspiraria dominar, no século XVIII, no mar de Bering; a Dinamarca pretenderia apropriar-se do estreito, entre as terras groelandesas e a Islândia.

Um século mais tarde, Alberico Gentile diria, em suas "ADVOCATIONES HISPANIAE":

"At ego quod olim scripsi, in libris belicis, territorium, et de terris dici, et de aquis"

E uma séria polêmica iria travar-se, entre Burcos e Graswinckel, àcerca dos direitos senhoriais das repúblicas italianas sobre a faixa de mar, adjacente a suas costas (vide GEorge Grafton Wilson, - "Les eaux adjacentes aux territoires des E'tats", "Recueil des Cours de L'Academie de Droit International”, vol. I. ${ }^{\circ} / 129$ )

Não é de espantar, pois, que os negociadores de 1494 hajam tambem dividido o Mar Oceano, - cincoenta anos antes das Preleções de Vittoria, cento e vinte anos antes de Grócio; dois séculos anteriormente ao aforisna de Bynkershoek. 
E, sôbre estas águas e litorais, Portugal e Espanha fizeram pairar o pacto colonial. Isto è: o fechamento dos portos ao comércio estrangeiro, o regimem que fazia depender o direito à mercancıa da prévia autorização do Conselho Ultramarino, ou dàa "Casa das Índias". E, por vezes, o monopólio, em beneficio das Companhias Gerais do Comercio, as grandes autarquias da época.

Ainda aqui, tal preceito se harmonizava com o Direito Internacional, então vigente. $\mathrm{E}$ a prova, temo-la na "Ordonnance", baixada em 1537 por Francisco I. ${ }^{\circ}$ de França. Na qual se cominavam, -

“expresses défenses aux sujets du Roi, tant généralement que particulièrement, qu'ils n'aient a voyager sur es-dites terres de Brésil et Maleguette, ni aux terres découvertes par les rois de Portugal, sous peine de confiscation de leurs navires, denrées et marchandises, et de tout ou un chacun de leurs biens, et punitions corporelles" (2).

$\mathrm{E}$ as leis internas dos Estados colonizadores o comprovam. Assim, nas sucessivas sesmarias e formais, que introduziram, entre nós, o regimen feudal das Capitanias, - El Rei concedia apenas aos senhores donatários a liberdade de comerciar com outra Capitania. O escambo in. ternacional continuava defeso. E, mesmo o comércio com a Metrópole vivia gravado de onus fıscais e de "restrições quantitativas". Algo que um escritor moderno chamaria, por certo, "contingentes de exportação"...

(2) "Terres de Maleguette" correspondem, no documento acima, à Costa da Guiné. (Vide "Les essais de colonisation en Amérique. - Histoire du Commerce de la France" - Art. Rousseau, edit.). 


\section{A LUTA COINTRA O MERIDIANO}

Tordesilhas representava uma vitória diplomática de Portugal.

Vitória, porém, incompleta e imprecisa. Incompleta, pois apenas se afrouxara o prodominio marítimo, que as Bulas de 1493 atribuiam à Espanha. Imprecisa porque se partilhara o vago, o desconhecido.

E não se sabia, ao menos:

a) O ponto de partida para o cômputo das longitudes;

b) o comprimento da "légua", que mederia o espaço entre êsse ponto de partida, e o círculo máximo, previsto no Acôrdo.

"Se sabe que la extensión de la legua maritima varia nó sólo segun los paizes "confessa SantiváÑEz, "sino que cada lugar ha ofrecido variaciones en diferentes epocas. Los náuticos en tiempo de la Conquista no estaban de accuerdo acerca de la verdadera extensión de la legua maritima, y esta fué una delas causas que concurrieron a oscurecer el celebre litigio, que respecto al término de sus respectivas jurisdiciones suscitó entre los dos primeros conquistadores del Peru, Pizarro y Almagro. (3).

Certo, já não era a imprecisão total da Bula, fruto da i apidez com que fôra conseguida. Já não se tomaria, simultaneamente, para meridiano inicial do cômputo, o que passasse. "por: Azores y Caboverde" — distantes entre si mais de cinco graus de longitude.

Partir-se-ia dos Açores. Mas de que ilha? E quai seria o comprimento das leguas, "contadas em graus, ou por outra maneira", no dizer do Tratado?

(3) Ap. Vicente QuesadA - História colonial argentina, pág. 23. 
Aos 13 de Julho de 1573, D. Miguel Lastarria, cosmógrafo dos Reis Católicos, e Francisco Fernandez, desenhista da Côrte Hispânica, compuseram o "mapa geográfico da América Meredional, de parte da África e de Ásia".

Nêle, vemos delineadas, a um tempo, três linhas possiveis de demarcação.

A primeira, - baseada no cômputo de " 26 1/2 legales de Castilla al grado", entraria pela costa do Ceará e sairia na altura da Baia de Todos os Santos.

A segunda, - tomando por base "20 legales maritimas al grado", correria da parte oriental do Maranhão até Angra dos Reis. A última, enfim, entendendo por léguas as "17 1/2 españolas y portuguesas al grado", alcançaria a costa sul-americana entre o Maranhão e o Pará, e engolfarse-ia no Oceano, nas proximidades de São Vicente.

Os cartógrafos portugueses, no entanto, Pedro Nunes e Francisco Teixeira deslocavam em seus mapas a posição continental. E' faziam incluir na órbita portuguesa superfícies muito ao sul do Rio da Prata, e, ao norte, até o Orenoco (4)

Esta ambiguidade se fez sentir desde o início.

o problema, porém, recrudesceu em 1518. Verificarase a esfericidade da terra. E mais, fazia-se mistér uma segunda linha divisória, a $180^{\circ}$ a W. do meridiano de Tordesilhas, para separar as terras do Oriente e os dominios espanhóes da Malásia e Melanésia.

Foi a questão das Molucas. $\mathrm{E}$ as Côrtes, que dantes buscavam ampliar seus quinhões na América, puzeram-se agora, a diminuil-os à porfia, Para que, por contra-golpe, em sua gléba se incluissem Java e Sumatra, as Célebes e as Filipinas.

A escritura de Saragoça resolveu momentâneamente a questão, entregando as ilhas a Portugal, mediante indeni-

(4) Vide o mapa en questão no livro A Colônia do Sacramento, de Jonathas da Costa Rego Monteiro, vol. II. ${ }^{\circ}$, pág. 112 (edição financiada pelo governo sul riograndense, - 1937). 
zação pecuniária. Mas deixava, no fundo, pendente 0 problema. Pois esta quantia devia ser devolvida, mediante cláusula de retrovenda, se, no futuro se provasse situaremse as Molucas no hemisfério luso...

Foi então, em 1532, que o Conde de Castanheira, secretário de Estado de D. João III $^{\circ}$ buscou alterar de fato - Tratado de Tordesilhas. E introduzir, em logar do critério de áreas diplomáticamente delimitadas, a noção do primeiro descobridor ou ocupante.

Incidente pouco estudado. Mas que consta de documento guardado no "Arquivo das Indias". Transcreveu-o JAIME CoRTESÃo, em seu longo estudo àcerca do "Domínio Ultramarino" (in "História de Portugal", - edição monumental, comemorativa do $80^{\circ}$ centenário da fundação da nacionalidade", vol. $6^{\circ}$, pág. 722 ).

Era a reivindicação lusa ao estuário do Prata, baseada em possiveis prioridades de navegação nessa latitude.

"Oferecer uma dúvida" anota o autor" citado, "era a únı́a esperança, e bem tenue, de sbtei: a aceitação da extranha proposta, que pretendia chã e amigavelmente rasgar o Tratado de Tordesilhas, ao sabôr das conveniências do momento."

Não se conhece, entre nós, o teor da resposta de Espanha. Foi negativa, por certo. Pois, em 1533, ad cautelam, D. João $\mathrm{III}^{\circ}$, ao instituir as Capitanias, não doou a totalidade do território americano que, de jure, lhe cabia.

Oquinhão mais meridional, - as Terras de Sant'Ana, — integrado na doação feita a Pero Lopes, mal alcançava o litoral catarinense. 
Deixava-se, ao sul, um largo claro, uma ampla Fronteira-zona entre os domínios das duas Côroas ibéricas.

De qualquer forma, era o terceiro critério sucessivo que Portugal aventava. Primeiro, os direitos decorrentes das bulas; depois, as estipulaçôes contratuais de Alcáçovas e Tordesilhas. Emfim, a descoberta ou ocupação, como se a América fosse ainda "res nullius".

\section{A EXPANSÃO COLONIAL}

Tordesilhas dava, em verdade, à Corôa Portuguesa, apenas $2.600 .000 \mathrm{kms}$. quadrados, na Amèrica Sulina.

Ainda assim, a princípio, baseados na multiplicidade das cartas, e desigualdade de critérios para a fixação da linha divisória, os espanhois procuraram incorporar a parte sul dessas possessões.

Ruy Moschera instala-se em Iguape. Assalta Santos. E somente abandona, com os seus, os territórios portugueses, antes a contra ofensiva dos piratininganos, chefiados por Jerônimo Leitão.

O título de jurisdição, dado pela Côrte de Madrí a Cabeza de Vacca, aos 15 de janeiro de 1540, inclui a Ilha de Santa Catarina. E é nestas águas que o explorador fundeia. E' de lá que parte, de pendões alçados, continente a dentro, a colonizar as terras, dantes doadas a Mendoza.

O escritor argentino AGUIRRE chega a afirmar haver o castelhano chantado

"sus armas en la Cananěa, como senãl y termino de su gobierno hacia el Brasil” (5)

No século XVII, porém, o oposto se verifica. São Paulo erguera-se no Altiplano. E passara rudemente a espraiar-se pelo sertão.

Ao fim da centúria precedente, já seus "bandeirantes" haviam atingido terras d'além-Tordesilhas. E varejado,

(5) Ap. Vicente Quesada, op., cit., pág. 104. 
com Braz Cubas, a área do Paramerim. Chegado ao médio Paranapanema, com Jerônimo Leitão, em 1581. E, com Nicolau Barreto, investido rumo ao Potosí, na primeira grande "bandeira" preadora de indios.

Entre 1580 e 1640, a união pessoal das Corôas ibéricas, sob a dinastia dos Felipes, embora conservando in nomine a soberania a Portugal, veio tirar, na realidade, o carater internacional à linha de 1494.

Embora Felipe II $^{\circ}$ e seus sucessores fossem, nominalmente, "reis de Espanha e Portugal", unindo apenas os títulos ao governo dos dois povos, pela fusão, em sua pessôa dos direitos dinásticos à sucessão das casas reinantes, não resta dúvida que a decisão das Côrtes de Thomar implicava na fusão dos impérios coloniais.

E a política absorvente do Conde-Duque de Olivares tendia a transformar essa união ratione personae em nex () real, implicando, por conseguinte, na creação de um único Estado soberano.

Consequência: - de facto, senão de jure, a linha separadora entre as Colônias espanhólas e lusas na América tornara-se simples limite administrativo.

Os paulistas aproveitam a situação. E invadem, mais e mais, o Vice-Reinado de Buenos-Aires e o Vice-Reinado do Perú.

Raposo Tavares e o clan dos Pedrosos destroem as Reduções Jesuiticas do Guayrá. Outros paulistas arrazam Ciudad-Real e Ontiveros, abrindo aos boiadeiros de Sorocaba a róta de expansão, rumo do Pampa.

Depois de 1640 , a independência portuguesa. Acendese a Guerra da Restauração, aquem e além mar. E, unidos num blóco, os "bandeirantes" marcham contra as possessões ultramarinas de Castela.

Combate-se, em 1641, em Mbororé, às margens do Uruguai. Fernão Dias Paes atinge o Rio Grande, com sua "Bandeira" apresadora. E o preamar paulista esten- 
de-se, num sucessivo erguer de povoações: Jaguariaiba, e Castro, e Ponta Grossa e Curitiba, e Santo Antônio dos Pinhais. .

Outra onda bandeirante, rumo a Oeste, destroi a provincia castelhana dos Itatins. Fxpulsa os espanhóis de Xerez. E Pascoal Moreira Cabral exerce, durante trinta anos, as funções de "fronteiro" luso, no Mboteteu, entre a Serra do Amambai e os pantanais do Mato Grosso. .

Uma terceira vaga paulista parte de São Vicente, pelo litoral. Funda Paranaguá, S. Francisco e Laguna. E, unida aos que vinham pelo sertão, entra no "Continente de São Pedro", e ocupa, em parte, a Vacaria.

Mais ao Sul, frente a Buenos Aires, tropas regulares do Rio e de São Paulo erguem a Colônia do Sacramento, e a mantêm, meses a fio, a enfrentar, um contra trinta, o cêrco de D. José de Garro e das milícias ibéro-americanas. (1680).

Os tratados de Haia e de Lisbôa, põem fim à guerra na Europa. Mas suas imprecisões em relação à Anérica Latina, a manútenção do duvidoso critério de léguas, e a revivescência do Meridiano de Tordesilhas mantêm, entre nós, o clima gerador de conflitos.

$\mathrm{E}$ tal "animus" persiste, mau grado novo Convênio, em 1681, que manda devolver Sacramento a Portugal.

"La diversa extensión de legua maritima y geográfica, usada em los dos paizes" explica ViCENTE QUeSADA, "venia a aumentar los embarazos; pues, mientras los españoles sostenian que debia emplear-se la legua catellana de. . $261 / 2$ al grado, los portugueses pretendian que fuesse la legua de $171 / 2$, occasionando esta circunstância diferencias muy grandes. " (op. cit., pág. 23). 
A guerra reacende-se, devido ao testamento de CarlosII. ${ }^{\circ}$, doando o trono espanhol a Felipe de Anjou. Portugal assina contra Luiz XIV o Tratado de 16 de Maio de 1703. E logo após, ingressa para a Aliança ofensiva e defensiva afim de impedir se confirme a união dos cetros de França e: de Castela.

O Conde das Minas toma Salamanca, vara a Guadarrama, e empossa em Madrí o Arquiduque d'Autria, como. Rei escudado no exército anglo-português de ocupação.

A luta atinge a América. Casais açorianos povoam. o Porto de Casaes. E a maré paulista, partindo de Laguna, atinge, no primeiro quartel do setecentismo, Rio Pardo, Santo Antônio da Patrulha, Santa Maria da Boca. do Monte.

Embalde a guerra com a França e Espanha termina. em 1715. Luta-se ainda e sempre na Colônia do Sacramento e na Campanha. João de Magalhães abre, em 1725, a passagem da Colônia ao Rio Grande, para facultar o apresamento dos gados às forças de Buenos Aires. Brito Peixoto devassa e conquista a Linha do Jacuí.

Em 1733 abre-se no pampa "a éra da estância" Enquanto isto, a mando do Governador de São Paulo (Conde de Sarzedas), Cristovam de Abreu tenta levantar os Minuanos, e assim neutralizar os esforços dos Tapes, aliados a Castela...

A Legião dos Voluntários Reais de São Paulo, e os Dragões do Rio Grande encetam, por volta de 1760, uma rude campanha de entreveros e guerrilhas, com os "terços" portenhos. Luta que perdurará, até 1776 .

(6) Virgtlio CORRÊA FILHo - Tragressẩo da Ráia Tordesilhana (IV.o), in "Jornal do Comércio" do Rio de Janeiro, 7 de maio de 1750.

(7) Correspondência do Conde de Sarzedas (Coleção dos. "Documentos Interessantes para a História e Costumes de São Paulo", edição do Arquivo do Estado, vol. 40). 
Enquanto 1s:o, ilavegantes fluviaes portugueses anexam, sem grande pugna, o vale do Amazonas. E um enorme "rush", motivado pela descoberta das jazidas de ouro levaria os paulistas ao desbravamento e conquista de Minas Geares, Mato Grosso e Goiảs...

Assim, a $1^{\circ}$ de Janeiro de 1750 , D. João $V^{o}$ de Portugal poderia jactar-se de estar na posse aproximada de 8.503.000 quilômetros quadrados na América. Ou seja, área três vezes e meia maior que a assinalada em Tordesilhas...

\section{A BUSCA DE UM CRITÉRIO FIXADOR DE FRONTEIRAS}

Ora, os negociadores do Tratado de Madrí não poderiam fixar-se, para início das negociações, nem nas Bulas Papais (cujo efêito jurídico, em Direito Internacional, os autores da época, como Wolff e Vattel punham em dúvida), nem nos precedentes acôrdos de Alcáçovas e Tordesilhas.

Verifica-se, há mais de um século, que as Molucas cabiam no hemisfério português. Mas a Espanha jamais cumprira a devolução dos 350.000 ducados a que se obrigára, pela cláusula $\mathrm{VII}^{\circ}, \mathrm{n}^{\circ} 3$, da escritura de Saragoça. $\mathrm{E}$ havia indebitamente colonizado as Filipinas.

Impossivel seria, por outro lado, obter o abandono da enorme área, que estava na posse efetiva de Portugai, para além do meridiano de 1494 .

Resolveram reconhecer, no preâmbulo,

"as dificuldades invenciveis que se offerecião se houvesse de assignalar-se esta Linha, com o conhecimento pratico, que se requer".

Reconheceram mais os excessos que, de uma parte e de outra, se haviam praticado. Historiaram suas respectivas impugnaçōes e agravos. Decidiram 
"pôr termo ás disputas passadas e futuras, e esquecer-se, e não usar de todas as ações e direitos que possam pertencer-lhes, em virtude dos referidos Tratados de Tordesilhas, Lisbôa, Utrecht, e da Escriptura de Saragoça, ou de quaisquer fundamentos que possão influir na divisão dos seus Dominios por linha Meridiana" (preâmbulo)

Estipularam, ao contrário, gue as novas divisas se assentaram segundo o critério de fronteiras, balizadas em

"paragens conhecidas, para que em nenhum tempo se confundão, como são a origem, o curso dos rios e os montes mais notaveis"

E mais:-

"que cada parte ha de ficar com o que actialmente possue, á excepcão das mutuas cessões que em seu logar se dirão" (ibidem)

Era o repúdio formal e explícito ao Meridiano. Era a idéia da "fronteira natural", em logar da artificial; a posse atual, predominando sobre o título.

Para obter esse resultado, os negociadores lusos renunciavam, em nome de seu soberano, às Filipinas. Abriam mão do credito provindo do Pacto de Saragoça Permutavam a Colônia do Sacramento pelos "Sete Povos das Missões", renunciando, de uma vez por todas, a qualquer reivindicação sobre o Estuário do Prata.

Bem podiam fazê-lo! Pois rezava o art. $1 .^{\circ}$, que

"o presente Tratado será o único fundamento e regra que ao diante se deverá seguir para a divisão e limite dos dois dominios em toda : a América e na Asia". 
Desapareciam os efeitos da Bula de Alexandre $\mathrm{VI}^{\circ}$ (melhor seria dizer, "das Bulas"), no que diz respeito à fronteira. Apagava-se a "linha de demarcação"; "para o futuro não se tratará mais dela", nem mesmo a título subsidiário, para o deslinde de dificuldades fronteiriças.

Os "confins dos Dominios das duas Monarchias" eram pormenorizadamente descritos, nos arts. $\mathrm{IV}^{\circ}$ a $\mathrm{IX}^{\circ} . \mathrm{E}$, para maior firmeza, os reis signatários prestar-se-iam auxilio para garantir "a pacifica posse e o uso livre e inteiro" dos respectivos quinhões.

Prometiam-se até cooperar militarmente para a repressão de invasões ou sublevações, que procurassem turbar-lhes o gôso dos direitos que do Tratado deçorram. Para a Espanha, a obrigação de garantia cobria o Amazonas, e o litoral português, dos Castilhos Grandes ao porto de Santos. Portugal acede, por seu lado, a garantir a costa hispânica até as margens do Orenoco, e, ao sul, até o Estreito de Magalhães. (art. 25).

Que importa, depois disso, que os Guaranís das Missões se sublevem, ou que o Brigadeiro Antônio Pedro de Vasconcelos, - governador da Colônia do Sacramento reclame ao Rei contra a cessão da fortaleza, que tanto sangue nos custára?

Sim! Porque, embora atacado pela opinião pública; embora anulado mais tarde pelos de El-Pardo; embora substituido pelos de Santo Ildefonso e Badajoz, -- o Tratado de Madrí consolidava a expansão final da América Portuguesa. Fruto da 256 anos de expansão, de guerras e lutas diplomáticas.

\section{A INTERPRETAÇÃO DO UTI-POSSIDETIS}

Esse uti-possidetis, que êle consagrava, em seu preâmbulo, serviria aliás, de norma-padrão à diplomacia do Império, em suas negociações com o Paraguai, a Bolivia, o Perú, e, até certo ponto, com o Uruguai. 
Alguns autores quizeram negar-lhe valôr jurídico, e substituil-o pelo "uti-possidetis de jure". Isto é, pela posse, decorrente do justo título.

Tal interpretação, porém não é justificável. Pois não mais se trata, em Madrí, de respeitar a "possessión" e a "casi-possessión" das Corôas como nos vetustos Tratados de Alcáçovas., em 1480.

Não mais se tutela a "quasi-posse", -_ isto é, a posse de direitos reais desmembrados da soberania;

$2^{\circ}$ ) - O Tratado de Madrí consagra, não o jus possidendi, derivante do dominio territorial ou soberania, mas o jus possessionis, que deflue da POSSE REAL, mesmo desprovida do justo título;

$3^{n}$ ) - Os signatários do Acôrdo declaram, com efeito, que os títulos anteriores serão esquecidos, "não se falará mais deles"; estatutem a mútua renuncia a quaisquer direitos e ações que deles possam emanar.

Logo, consagravam o util-possidetis de facto. Cobriam-no com suas estipulações, e convalidavam, assim, a prescrição aquisitiva (que, segundo VERDROSS, - é um dos principios gerais de direito, aplicáveis ao campo internacional);

$\left.4^{\circ}\right)$ - Cumpre notar, aliás, que o uti-possidetis de fato era, na realidade, o único que poderia, em 1750, servir de deslinde à raia divisória. Do contrário, seria reabrir o debate das passadas pendências, a que o Tratado visava expressamente pôr fim.

$\left.5^{\circ}\right)$ - Sòmente êle

"está demonstrado por estabelecimentos, povoações, ou outros monumentos de posse, que se vêem, ou se tocam", 
como relembra, aliás, a nota paraguaia à Côrte do Rio de Janeiro, em Abril de 1856.

$\left.6^{\circ}\right)$ - Admitir o uti-possidetis de jure seria, no dizer do juris-consulto colombiano, DR Florentro Gonzales, tirar os direitos

"más bien del título de derecho con que se posee, que de la misma posesión".

E comenta o Prof. argentino, Dr. José Leon Suárez, em conferência realizada no Rio de Janeiro, em 1918: -

“. . en tal caso, no es posesión, es derecho, fundado en titulos hereditarios, y lo que correspondía era invocar el jus y no la possessio, es decir, la formula inversa del tan mentado primer principio de derecho americano". (El uti-possidetis y los limites americanos", in "Diplomacia Universitária Americana”, Buenos-Aires, 1918, pág. 60.)

Urge terminar. O tratado de 1750 é, a nosso vêr, o marco crucial de nossa história diplomática.

Pouco importa que, assinado para estar "em perpétuo vigôr entre as duas Corôas" (art. 26), haja sido cancelado onze anos mais tarde, pelo art. $1^{\circ}$ do Tratado de El-Pardo.

Os principios que aceitou, a posse que transformou em domínio, - isto é, em soberania territorial, - o uti possidetis, que foi o primeiro a afirmar, no Novo Mundo, constituem a confirmação das conquistas de nossos Bandeirantes e Fronteiros, orientados, de longe, pelo Conselho Ultramarino.

A América Portuguesa surgiu ali, consolidada de jure em suas fronteiras.

É êle que sobrevive, nos pactos, que óra traçam os limites de nosso território. 